\title{
Levothyroxine sodium oral solution to control thyroid function in a patient with hypothyroidism and celiac disease
}

\author{
Ernest Asamoah ${ }^{1}$ \\ ${ }^{1}$ Community Physicians Network
}

December 22, 2020

\begin{abstract}
A patient with hypothyroidism, Addison's disease, and celiac disease had persistent hypothyroid symptoms, and frequent fluctuations in TSH, prompting transition to L-T4 sodium oral solution (Tirosint@-SOL). Implementing a gluten-free diet and switching to the oral solution significantly improved malabsorptive and subsequent hypothyroid symptoms without the need to increase L-T4 dosage.
\end{abstract}

\section{Hosted file}

Dr Asamoah Manuscript_Final Draft.pdf available at https://authorea.com/users/384456/ articles/500065-levothyroxine-sodium-oral-solution-to-control-thyroid-function-in-apatient-with-hypothyroidism-and-celiac-disease 